\title{
ABO Blood Types and Risk of Testicular Cancer in Turkish Population: Preliminary Results
}

\author{
( ) Şebnem İzmir Güner ${ }^{1}$, ๑ Ekrem Güner ${ }^{2}$ \\ ${ }^{1}$ Memorial Şisli Hospital, Haematology and Bone Marrow Transplantation Center, Istanbul, Turkey \\ 2 University of Health Sciences, Bakırköy Dr.Sadi Konuk Training and Research Hospital, Clinic of Urology, Istanbul, Turkey
}

\begin{abstract}
Objective: $\mathrm{ABO}$ blood type has been reported to be associated with various types of cancer such as lung cancer, prostate cancer, bladder cancer and pancreatic adenocarcinoma. We aimed to determine whether there is a relationship between $A B O$ blood subtypes and testicular cancer incidence in Turkish population.

Materials and Methods: We retrospectively analyzed the medical records of all patients who underwent inguinal orchiectomy in our department between 2008 and 2018.

Results: A total of 138 patients were included in the study. The age of the patients ranged from two to 67 years, with a mean age of $32.9 \pm 10.9$ years. Of the 138 participants, 45 (32.6\%) had blood type A, 27 (19.6\%) had blood type B, 50 had blood type O (36.2\%) and 16 (11.6\%) had blood type $A B$. One hundred and twenty-five patients (90.6\%) were Rhesus (+) and 13 patients (9.4\%) were Rhesus (-). There was no statistically significant difference between $A B O$ blood subtypes according to testicular pathology $(p=0.713)$. Interestingly, the percentage of patients with $A B$ blood subtype was the lowest.

Conclusion: These results suggest that Turkish men with O blood subtype and Rh (+) are prone to develop testicular cancer. However, these findings should be supported by further studies conducted with a large number of participants.

Keywords: Testicular cancer, blood group, ABO, rhesus

\section{Introduction}

$\mathrm{ABO}$ blood type was first discovered by Karl Landsteiner in 1900 and has been widely studied in various diseases and blood transfusion complications (1). ABO blood type was suggested to be associated with various types of cancer such as lung cancer (2), prostate cancer, bladder cancer (3) and pancreatic adenocarcinoma (4).

To the best of our knowledge, there is no study in the literature on the relationship between $\mathrm{ABO}$ blood types and testicular cancer. In the present study, we aimed to determine whether there is a relationship between $\mathrm{ABO}$ blood subtypes and testicular cancer incidence.

\section{Materials and Methods}

After obtaining approval from the Local Ethics Committee (2018/350), we retrospectively analyzed the medical records of all patients who underwent inguinal orchiectomy in our department between 2008 and 2018. The parameters examined included demographics, testicular cancer pathology results and $\mathrm{ABO}$ blood subtypes. All male patients diagnosed with testicular cancer without an age limitation were included the study. Patients with a final pathology result consistent with benign pathologies or other malignancies such as lymphoma and rhabdomyosarcoma were excluded from the study. The patients were divided into two groups according to the final pathology results; Group 1: seminoma and Group 2: non-seminomatous germ cell tumors (Figure 1,2).
\end{abstract}

Cite this article as: Güner \$̧, Güner E. ABO Blood Types and Risk of Testicular Cancer in Turkish Population: Preliminary Results. Bull Urooncol 2019;18(4):135-137

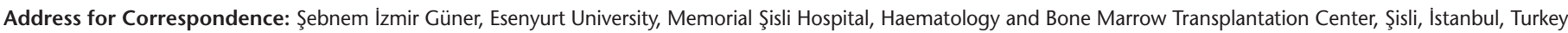
E-mail: ekremguner@yahoo.com ORCID-ID: orcid.org/0000-0002-6326-9424 Received: 11.10.2013 Accepted: 11.10.2013 


\section{Statistical Analysis}

Statistical analysis was performed using IBM SPSS Statistics for Windows v.21.0 (IBM Corp., Armonk, NY). Quantitative values were expressed as mean \pm SD or median (range), whereas

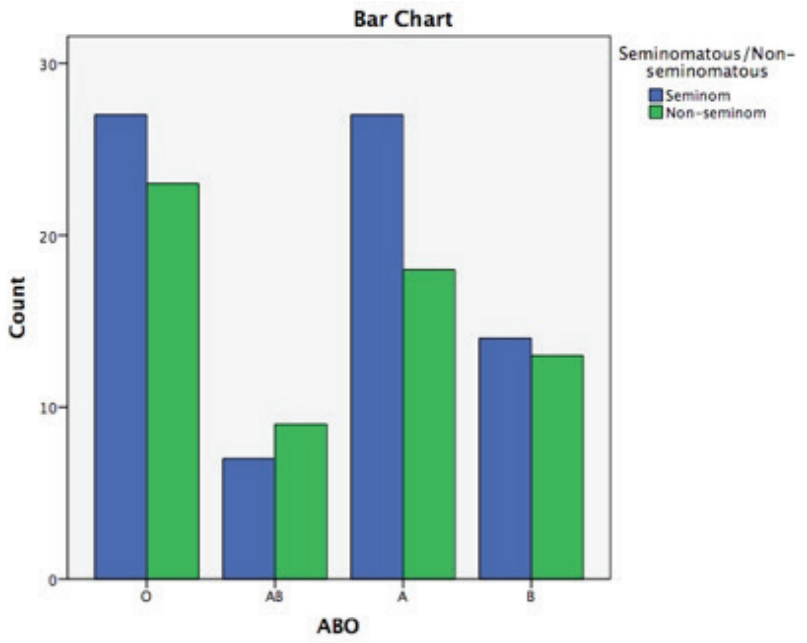

Figure 1. Distribution of $A B O$ blood types according to pathology

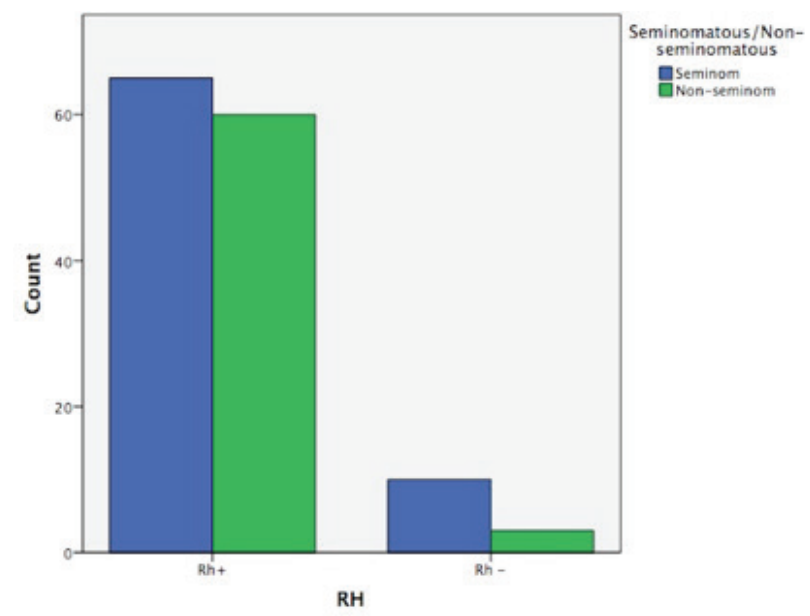

Figure 2. Distribution of Rhesus blood types according to pathology

\begin{tabular}{|c|c|c|c|c|}
\hline $\begin{array}{l}\text { Blood } \\
\text { Subtypes }\end{array}$ & Rhesus & $\begin{array}{l}\text { Seminomatous } \\
(n=77)\end{array}$ & $\begin{array}{l}\text { Non-seminomatous } \\
(n=63)\end{array}$ & $P$ value \\
\hline \multirow{2}{*}{ Group A } & $\mathrm{Rh}(+)$ & $25(33.3 \%)$ & $17(27 \%)$ & \multirow[t]{4}{*}{$0.222^{*}$} \\
\hline & $\mathrm{Rh}(-)$ & $2(2.7 \%)$ & $1(1.6 \%)$ & \\
\hline \multirow[t]{2}{*}{ Group B } & $\mathrm{Rh}(+)$ & 11 (14.7\%) & 12 (19\%) & \\
\hline & $\mathrm{Rh}(-)$ & $3(4 \%)$ & $1(1.6 \%)$ & \\
\hline \multirow[t]{2}{*}{ Group AB } & $\mathrm{Rh}(+)$ & $6(8 \%)$ & $8(12.7 \%)$ & \multirow[t]{4}{*}{$0.713^{\#}$} \\
\hline & $\mathrm{Rh}(-)$ & $1(1.3 \%)$ & $1(1.6 \%)$ & \\
\hline \multirow[t]{2}{*}{ Group O } & $\mathrm{Rh}(+)$ & $23(30.7 \%)$ & $23(36.5 \%)$ & \\
\hline & $\mathrm{Rh}(-)$ & $4(5.3 \%)$ & $0(0 \%)$ & \\
\hline
\end{tabular}

qualitative values as numbers and percentages. Shapiro-Wilk test was used to determine whether the values were normally distributed or not. Cross table analysis, chi-square test and Fisher's exact test were applied to compare the qualitative characteristics of the two groups. The level of statistical significance was set at $p<0.05$.

\section{Results}

A total of 138 patients were included the study. The mean age of the patients was $32.9 \pm 10.9$ years, ranging from 2 to 67 years. Of the 138 participants, 45 (32.6\%) had blood type A, 27 (19.6\%) had blood type B, 50 had blood type O (36.2\%) and $16(11.6 \%)$ had blood type $A B$. One hundred and twentyfive patients (90.6\%) were Rhesus (+) and $13(9.4 \%)$ were Rhesus (-). Final pathological examination revealed seminoma in $75(54.3 \%)$ patients, malign mix germ cell tumor in 45 (32.6\%) patients and germ cell tumors in 18 (13\%) patients. There was no statistically significant difference between $A B O$ blood subtypes according to testicular pathology $(p=0.713)$. Interestingly, the percentage of patients with $A B$ blood subtype was the lowest. There was no statistically significant difference in rhesus status of patients with seminomatous and nonseminomatous pathology $(p=0.142)$ (Table 1$)$.

\section{Discussion}

Testicular cancer accounts for 1-2\% of all tumors in men and it is the most common cancer in young men between the ages of 15-34. There is a significant geographical variation in the age-standardized incidence of testicular cancer; such the incidence is $0.5 / 100.000$ in Egypt and 9.6/100.000 in Norway (5). There are several risk factors for testicular cancer including cryptorchidism, ethnicity, racial differences and genetic causes, such as Down syndrome and testicular dysgenesis syndrome $(6,7)$.

The $A B O$ blood grouping system was described in the early 1900s. This grouping system is based on the expression of $A$ and $B$ blood cell surface antigens. The absence of both antigens results in the $O$ phenotype. $A B O$ blood group was found to be associated with numerous diseases and hemostatic complications such as increased risk of coronary artery disease and venous thromboembolism in patients with non-O blood type (8).

Several studies have been conducted to determine the possible relationship between $A B O$ blood types and cancer $(4,9)$. The frequently studied cancers include breast cancer (10), gastric cancer (11), lung cancer (2), and bladder, prostate and kidney cancers $(3,12,13,14)$.

In a study by Meo et al. (10), blood group A was found to have the highest association with breast cancer compared to other blood groups. The incidences of breast cancer in blood groups $A, B, O$ and $A B$ were $45.88 \%, 16.6 \%, 31.69 \%$, and $6.27 \%$, respectively. They also reported that "Rhesus + " blood group had higher incidence of breast cancer compared to "Rhesus -" (87.31\% vs $11.68 \%)$.

$\mathrm{Xu}$ et al. (11) studied the relationship between $A B O$ blood types and gastric cancer prognosis in 1412 patients who were 
diagnosed with gastric cancer and underwent surgery. They concluded that non-AB blood groups were associated with poor prognosis.

In another study, Stakisaitis et al. (3) aimed to reveal the association between $\mathrm{ABO}$ blood polymorphisms and various urological cancers including prostate, bladder and kidney. They found a significantly higher incidence of prostate cancer in patients with blood group $B(p<0.05)$. The incidence of bladder cancer was also higher in men with blood group $B(p<0.04)$. $\mathrm{ABO}$ blood subtype $\mathrm{O}$ was associated with a decreased risk of bladder cancer in women $(p<0.05)$. No significant difference was observed in kidney cancer in terms of $A B O$ blood subtypes. To the best of our knowledge, there is no study in English literature examining the association between $A B O$ blood subtypes and testicular cancer in men. In a unique study by Yildiz et al. (15), the authors investigated the effect of $A B O$ blood subtype on prognosis in patients with non-seminomatous testicular cancer who were treated with high dose chemotherapy and autologous stem cell transplantation. ABO blood subtypes and Rhesus distribution of patients in this study were as follows: A subtype in 19 (29.7\%), B subtype in seven (10.9\%), O subtype in 34 (53.1\%), AB subtype in four (6.3\%), Rh (+) in 61 $(95.3 \%)$ and $\mathrm{Rh}(-)$ in three $(4.7 \%)$ patients. They found that overall survival of patients with $\mathrm{O}$ blood subtype was longer than other blood subtypes; however, it was not statistically significant $(p=0.071)$. One-year progression-free survival was also higher in patients with $\mathrm{O}$ blood subtype compared to all other groups (79.1\% vs $65.2 \%, p=0.19)$ : however, it was also not statistically significant. In concordance with Yildiz et al. (15), most of the patients in our cohort had blood subtype $O$ (36.2\%) and the patients with $A B$ blood subtype constituted the lowest percentage (11.6\%). Also, $90.6 \%$ of the patients were Rhesus (+).

\section{Conclusion}

These results suggest that Turkish men with $O$ blood subtype and Rhesus (+) are prone to develop testicular cancer. However, these findings should be supported by further studies conducted with large number of participants.

\section{Ethics}

Ethics Committee Approval: Ethical approval was obtained from Bakırköy Dr. Sadi Konuk Training and Research Hospital Ethics Committee (no: 2018/350).

Informed Consent: There is no need informed consent form due to the study is retrospective.

Peer-review: Internally and externally peer-reviewed.

\section{Authorship Contributions}

Concept: Ş.I.G., E.G., Design: Ş.I.G., E.G., Data Collection or Processing: Ş.I.G., E.G., Analysis or Interpretation: Ş.I.G., E.G., Literature Search: Ş.I.G., E.G., Writing: Ş.I.G., E.G.

\section{Acknowledgements}

Publication: The results of the study were not published in full or in part in form of abstracts.

Contribution: There is not any other contributors who may not be listed as authors.

Conflict of Interest: No conflict of interest was declared by the authors.

Financial Disclosure: The authors declared that this study received no financial support.

\section{References}

1. Sun W, Wen CP, Lin J, et al. ABO blood types and cancer risk--a cohort study of 339,432 subjects in Taiwan. Cancer Epidemiol 2015;39:150-156.

2. Urun $Y$, Utkan $G$, Cangir $A K$, et al. Association of $A B O$ blood group and risk of lung cancer in a multicenter study in Turkey. Asian Pac J Cancer Prev 2013;14:2801-2803.

3. Stakisaitis $D$, Jukneviciene $M$, Ulys $A$, et al. $A B O$ blood group polymorphism has an impact on prostate, kidney and bladder cancer in association with longevity. Oncol Lett 2018;16:1321-1331.

4. Iodice $\mathrm{S}$, Maisonneuve $\mathrm{P}$, Botteri $\mathrm{E}$, et al. $\mathrm{ABO}$ blood group and cancer. Eur J Cancer 2010;46:3345-3350.

5. Manecksha RP, Fitzpatrick JM. Epidemiology of testicular cancer. BJU Int 2009;104:1329-1333.

6. Smith ZL, Werntz RP, Eggener SE. Testicular Cancer: Epidemiology, Diagnosis, and Management. Med Clin North Am 2018;102:251-264.

7. Holzik MFL, Rapley EA, Hoekstra HJ, et al. Genetic predisposition to testicular germ-cell tumours. The Lancet Oncology 2004;5:363-371.

8. Rummel SK, Ellsworth RE. The role of the histoblood ABO group in cancer. Future Sci OA 2016;2:FSO107.

9. Zhang $B L, H e N$, Huang $Y B$, et al. $A B O$ blood groups and risk of cancer: a systematic review and meta-analysis. Asian Pac J Cancer Prev 2014; 15:4643-5460.

10. Meo SA, Suraya F, Jamil B, et al. Association of ABO and Rh blood groups with breast cancer. Saudi J Biol Sci 2017;24:1609-1613.

11. Xu YQ, Jiang TW, Cui YH, et al. Prognostic value of ABO blood group in patients with gastric cancer. J Surg Res 2016;201:188-195.

12. Joh HK, Cho E, Choueiri TK. ABO blood group and risk of renal cell cancer. Cancer Epidemiol 2012;36:528-532.

13. Cartwright RA, Adib R, Appleyard I, et al. ABO, MNSs and rhesus blood groups in bladder cancer. Br J Urol 1983;55:377-381.

14. Klatte $T$, Xylinas $E$, Rieken $M$, et al. Impact of $A B O$ blood type on outcomes in patients with primary nonmuscle invasive bladder cancer. J Urol 2014;191:1238-1243.

15. Yildiz B, Erturk I, Karadurmus $\mathrm{N}$, et al. Prognostic value of $A B O$ blood group in patients with nonseminomatous testicular cancer who treated with autologous stem cell transplantation. Journal of Oncological Sciences 2018;4:70-73. 